\title{
COVID-19 Pandemic and Sub-Replacement Fertility
}

\author{
shahul ebrahim ${ }^{1}$, yusuf ahmed ${ }^{2}$, and Rubina Imtiaz ${ }^{3}$ \\ ${ }^{1}$ University of Sciences Techniques and Technologies of Bamako \\ ${ }^{2}$ University of Zambia School of Medicine \\ ${ }^{3}$ Taskforce for global health
}

August 23, 2020

As the COVID-19 pandemic continues to surge, the conjectured linkages between pandemics, fertility, and child health observed during the great depression of 1957 in the USA and the influenza pandemic of 1918 in the USA and Japan become highly relevant. ${ }^{1,2}$ From 1900s through 1970s, along with the economic and epidemiologic transitions, standardized child mortality from infectious diseases decreased by $90 \%$ overall, birth defects remained the leading cause of ill health, and fertility rates declined. Pre-COVID-19 fertility projections for 2020 indicate that 66 countries of the countries currently experience sub-replacement fertility (Figure), below the global average fertility of 2.3 and the sub-replacement fertility level of $2.1 .^{3}$ The fertility rate of 2.1 as the sub-replacement level is derived from the assumption that, in a community, two children per women are required to replace parents and 0.1 child to make up for child mortality prior to becoming an adult. Fertility rate at or below 1.7 is considered severe ( 45 countries) because interventions (excluding immigration of populations with high fertility) are unlikely to achieve the 2.1 replacement target.

Impact of Pandemics on Fertility and Child Health

Pandemics can adversely affect both fertility and child survival. ${ }^{1,2}$ The mechanisms that linked pandemics with subsequent depressed fertility during the past pandemics include a combination of reduced conceptions and embryonic losses during the first month of pregnancy, individual level stress from pandemics and pandemic-related mortality, short-run instability from environmental shocks and economic volatility leading to decreased investment in the population size of future generations.

Child development may be affected by community mitigation activities including home quarantine, social distancing, and closing of economic and travel activities, reduced access to child day care, interruption in schooling and nutrition opportunities for many children. These effects are amplified if the child is cared for by single parents or parents in employment categories such as the service sector that is immediately affected by mitigation strategies. We lack contemporary studies on the impact of these outcomes. Social and family structures during historic events differed greatly from that of today. In countries that experience sub replacement fertility, population of childbearing age is characterized by single households, increased mean age of women at first birth (higher order births), nuclear families, increased participation of women in the workforce, high percentage of dissolved family unions, and inadequate unemployment benefits and social support systems to support families. ${ }^{4 \text {, }}$

The evolution of the COVID-19 pandemic occurred in a condensed timeframe and SARS-CoV-2 related embryonic loss has not been reported. With the addition of COVID-19 related childhood multisystem inflammatory syndrome to birth defects (current burden in developed countries, 40 to 55 per 1000 live births ${ }^{5}$ ), the overall child morbidity will increase. The spread of COVID-19 and mortality has been significant among many of the countries that experience sub replacement fertility and the incidence is increasing in the younger ages as currently observed in the U.S. COVID -19. Mitigation efforts can adversely impact child 
survival and fertility decisions due to changes in ratio of workers to dependents, changes in the labor supply of working-age adults over time, and changes in the average level of schooling.

Given that the countries that face sub-replacement fertility are also the leading drivers of innovation and productivity globally (figure) $)^{3,6}$, further stress on fertility in these countries will no doubt impact their economic security and contribution to global development in the next two decades.

Actions to Improve Fertility and Improve Child Well Being

Countries in sub-replacement fertility status have explored social, economic, and policy interventions to reverse the trend. They include policies to balance work and family obligations, financial incentives (fertility boosters, monthly childcare benefit linked to family size), speed premium (financial incentives for delivery of second child within a given time frame), free childcare, and housing subsidies. ${ }^{7}$ Immigration played a major role in sustaining fertility rates at replaceable levels in the USA. The easing of the one-child policy in China in 2016 increased the number of births by $8 \%$ over 2015. Given that fertility change is a longterm cohort effect, influenced by various exogenous factors, select measures are unlikely to achieve long-term benefits unless a complete set of supportive interventions across the lifespan of the parents and child are implemented in concert.

Unlike during historic events, COVID-19's impact on fertility should be of concern for relevant countries. Efforts to aid population growth and health outcome of children born today are needed in high-risk countries so that many more women achieve healthy reproductive goals and their children achieve optimal health. We highlight 7 actions points below.

- Strengthen and expand newborn screening programs to identify and provide early intervention for birth defects and assure special care the affected children.

- Educate the public about steps that fathers and communities can take to support women to achieve healthy reproductive outcomes.

- At the policy level, use COVID-19 as an opportunity to advocate, develop and integrate to social programs and labor sector a comprehensive list of supportive interventions across the life span of the parent-child dyad.

- Integrate pre-conception care concepts to clinical practice to enable women of childbearing age to achieve optimal mental and physical health during COVID-19 and ensure a healthy balanced diet, including folic acid fortification or supplementation, correcting iodine deficiencies and avoiding teratogens such as alcohol and tobacco.

- Optimize maternal health through control of chronic diseases that increases a woman's risk for both COVID-19 and adverse child outcomes.

- Among intrauterine and child survivors of COVID-19, monitor potential long term impact of COVID-19 throughout the child's growth and development period.

- Assure the continuity and comprehensiveness of high-quality child education and social interaction opportunities through innovative virtual programs when in-person education is unavailable.

With the aging of populations and the interconnectedness of our economies, COVID-19's potential impact in countries that are already facing sub-replacement fertility should receive due consideration in programs aimed at improving the health of the mother and child. Doing so would be a necessity not only form a national security perspective, but from a long-term economic prosperity, not just for those countries at high risk, but for all countries.

Summary (optional)

Pandemics can adversely affect both fertility and child survival. The pathways include adverse biological outcomes (those caused as a direct result of infections on fetus, newborn, or children), ecological impact on fertility (due to indirect causes that leads to postponement or lack of reproduction), and as a result of unintended consequences of community mitigation on growth and development of children ${ }^{1-4}$ Globally 66 countries, mostly those the global innovation hubs with the highest per capita GDP, already have fertility 
rates below 2.1, of which 45 are at or below the irreversible rate of 1.7. As COVID-19 incidence is increasing in the younger ages, population growth plans to avert further deterioration of fertility and assure optimal health of children are needed in countries with sub-replacement fertility.

Figure. Countries facing sub-replacement fertility $(\mathrm{TFR}<2.1)$, their global ranking by per-capita gross domestic product (GDP) and innovation index ${ }^{1,6} \cdot$ Fertility rates below 1.8 marked by vertical blue line are considered irreversible

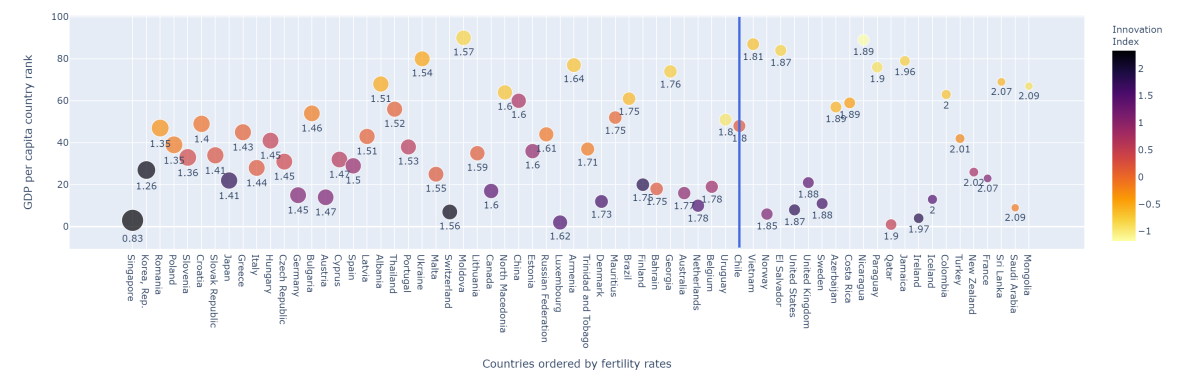

References

1. Schneider, D. The Great Recession, Fertility, and Uncertainty: Evidence From the United States. Fam Relat 2015, 77: 1144-1156. doi:10.1111/jomf.12212

2. Chandra S, Yu YL. The 1918 influenza pandemic and subsequent birth deficit in Japan. Demographic Research. 2015 Jul 1;33:313-26.

3. The World Factbook. Country comparison: total fertility rate. https://www.cia.gov/library/publications/the-world-factbook/rankorder/2127rank.html. Accessed May 25, 2020.

4. Brinton MC, Bueno X, Oláh L, Hellum M. Postindustrial fertility ideals, intentions, and gender inequality: A comparative qualitative analysis. Population and development review. 2018 Jun;44(2):281-309.

5. March of Dimes Birth Defects Foundation. Global report on birth defects. White Plains, New York 2006. https://www.marchofdimes.org/global-report-on-birth-defects-the-hidden-toll-ofdying-and-disabled-children-full-report.pdf

6. Global Innovation Index 2020. https://www.globalinnovationindex.org/Home. Cornell University, INSEAD WIPO. Accessed June 15, 2020

7. United Nations. Population Division. Government policies to raise or lower the fertility level. https://www.un.org/en/development/desa/population/publications/pdf/popfacts/PopFacts_2017-10.pdf. accessed May 15, 2020. 